\title{
Differences Between Ascospores and Conidia of Didymella rabiei in Spore Germination and Infection of Chickpea
}

\author{
Antonio Trapero-Casas and Walter J. Kaiser
}

First author: Departamento de Agronomía, ETSIAM, Universidad de Córdoba, Apartado 3048, 14080-Córdoba, Spain; and second author: 3394 Chickory Way, Boise, ID 83706.

Accepted for publication 2 July 2007.

\section{ABSTRACT}

Trapero-Casas, A., and Kaiser, W. J. 2007. Differences between ascospores and conidia of Didymella rabiei in spore germination and infection of chickpea. Phytopathology 97:1600-1607.

Studies were performed to compare the germination and infection of ascospores and conidia of Didymella rabiei under different temperature and moisture conditions. Germination of ascospores and conidia on cover glasses coated with water agar began after $2 \mathrm{~h}$, with maximum germination $(>95 \%)$ occurring in $6 \mathrm{~h}$ at $20^{\circ} \mathrm{C}$. No germination occurred at 0 and $35^{\circ} \mathrm{C}$. Ascospores germinated more rapidly than conidia at all temperatures. Germination declined rapidly as the water potential varied from 0 to $-4 \mathrm{MPa}$, although some germination occurred at $-6 \mathrm{MPa}$ at 20 and $25^{\circ} \mathrm{C}$. Ascospores germinated over a wider range of water potentials than conidia and their germ tubes were longer than those of conidia at most water potentials and temperatures. The optimum temperature for infection and disease development by both ascospores and conidia was around $20^{\circ} \mathrm{C}$. Disease severity was higher when ascospores were discharged directly onto plant surfaces from naturally infested chickpea debris compared with aqueous suspensions of ascospores and conidia sprayed onto plants Disease severity increased as the length of the wetness period increased. When dry periods of 6 to $48 \mathrm{~h}$ occurred immediately after inoculation, disease severity decreased, except for the shorter periods which had the opposite effect. Disease severity was higher with ascospore inoculum when no dry periods occurred after inoculation.

Additional keywords: Ascochyta blight, Cicer arietinum.
Ascochyta blight caused by Ascochyta rabiei (Pass.) Labrousse is an important disease of chickpea (Cicer arietinum L.) in many countries $(12,19,22)$. Infected seed is important in the spread and survival of the pathogen $(12,19)$. The fungus may spread from infected seed to germinating seedlings, inducing lesions on the foliage. Pycnidia develop in the lesions and ooze conidia during periods of cool, wet weather. The conidia are splash dispersed by rain to adjacent plants. Only the fungal anamorph, A. rabiei, develops on infected chickpea plants during the growing season. Conidia from seedlings infected from seed and overwintered infested chickpea debris may serve as important sources of primary inoculum in the early stages of the crop or may provide the inoculum necessary for secondary infections later in the growing season.

In nature, Didymella rabiei (Kovachevski) v. Arx (syn. Mycosphaerella rabiei Kovachevski), the teleomorph of A. rabiei, develops and overwinters only on infested chickpea debris on the soil surface when certain conditions are met $(18,25)$. The fungus is heterothallic (25) and requires the pairing of two compatible mating types, referred to as MAT1-1 and MAT1-2, for fertile pseudothecia to develop. The discharge of ascospores usually coincides with the onset of the vegetative growth of the chickpea crop. The teleomorph plays an important role in the epidemiology of Ascochyta blight of chickpea in Spain $(18,26)$, the United States (25), and possibly in Australia (6), Canada (4), Iran (14), Israel (7), Syria (9), and Turkey (13). Ascospores are important in the long distance spread of the fungus in the early stages of the crop (in spring) and may provide the primary inoculum required for development of disease epidemics $(25,26)$.

Corresponding author: A. Trapero-Casas; E-mail address: trapero@uco.es

doi:10.1094/PHYTO-97-12-1600

(c) 2007 The American Phytopathological Society
Although much research has been done on the biology of Ascochyta blight and its control $(19,22)$, information on the precise effects of environmental variables on the disease or on the pathogen under controlled conditions is scarce $(19,24)$. The optimum temperature for mycelial growth, pycnidial formation, and conidial germination of different isolates of $A$. rabiei is about $20^{\circ} \mathrm{C}$, with lower and upper limits around 0 to $5^{\circ} \mathrm{C}$ and 30 to $32^{\circ} \mathrm{C}$, respectively $(11,15,19,28)$. The effect of temperature for infection by conidia is similar to the in vitro effect of temperature on growth of the fungus $(24,27)$. The regression model developed by Trapero-Casas and Kaiser (24) fitted to infection data and predicted a minimum wetness period of $7.6 \mathrm{~h}$ for significant infection at the predicted optimum of $21.2^{\circ} \mathrm{C}$. At temperatures lower and higher, longer periods of wetness were required for significant infection, mainly outside the range of 15 to $25^{\circ} \mathrm{C}$.

The effect of temperature on ascospore germination and of moisture on germination of conidia and ascospores has not been investigated. Moreover, the comparative ability of ascospores and conidia of this pathogen to infect chickpea is unknown. This information would help determine environmental conditions necessary for plant infection and to explain results of the influence of temperature, relative humidity $(\mathrm{RH})$, and wetness period on infection and development of Ascochyta blight of chickpea. The objectives of this study were to (i) determine the effects of temperature and moisture and their interaction on germination and germ tube elongation of ascospores and conidia of D. rabiei; and (ii) compare the infection ability of ascospores and conidia on chickpea at different temperatures and leaf wetness periods.

\section{MATERIALS AND METHODS}

Isolates and inoculum production. Two compatible isolates of D. rabiei from Córdoba, Spain were used in all spore germination experiments. These were AR 8101 (MAT1-1) and AR 8302 (MAT1-2). Conidial suspensions were prepared from 5- to 7-day- 
old cultures on chickpea seed meal-dextrose agar (CDA) (24). The suspensions were adjusted with sterile distilled water to $1 \times$ $10^{5}$ conidia per ml. Ascospores of $D$. rabiei were obtained by inoculating sterile chickpea stem pieces with a conidial suspension of both compatible isolates. After incubation on moist filter paper at $8^{\circ} \mathrm{C}$ for about 60 days, small pieces of dried stem tissue containing mature pseudothecia were placed on $2 \%$ water agar (WA) blocks that were attached to the inner surface of petri dish lids for discharge of ascospores. Ascospore suspensions were adjusted to $5 \times 10^{4}$ spores per $\mathrm{ml}(25)$.

Effect of temperature on spore germination and germ tube elongation. To determine the influence of temperature on spore germination and germ tube elongation, drops $(5 \mu \mathrm{l})$ of conidial suspensions were placed in the center of microscope cover glasses $(20 \times 20 \mathrm{~mm})$ coated with WA. Ascospores were discharged directly from the chickpea stem tissues covered with pseudothecia onto WA-coated cover glasses. The cover glasses were incubated at $100 \%$ relative humidity $(\mathrm{RH})$ in the dark at $0,5,10,15,20,25$, 30 , and $35^{\circ} \mathrm{C}$. At $2 \mathrm{~h}$ intervals from 0 to $24 \mathrm{~h}$ and $8 \mathrm{~h}$ intervals from 24 to $48 \mathrm{~h}$, one cover glass was removed from each temperature and inverted on the top of a drop of acid fuchsin in lactophenol, and germination and germ tube growth were observed under a microscope. Percent spore germination was determined by observing 60 conidia or ascospores selected at random on each cover glass. A spore was considered germinated if the germ tube was at least one-half the longitudinal axis of the spore.

For each temperature, a mean germination time (MGT) was calculated by the following formula:

$$
M G T=\frac{\sum \Delta G_{i} \times t_{i}}{G_{\max }}
$$

where $\Delta G_{i}$ is the increase in the percentage of germinated spores at each 2-h interval $\left(G_{i}-G_{i-1}\right), t_{i}$ is the average number of hours for each time interval $\left(t_{i}+t_{i-1} / 2\right)$, and $G_{\max }$ is the percentage of germinated spores for each temperature at $48 \mathrm{~h}$. The parameter MGT is expressed in hours and it coincides with the area above the curve of germination over time. A germination rate (GR) was calculated as the inverse of MGT: GR $=1 /$ MGT (expressed as $\mathrm{h}^{-1}$ ).

Average germ tube length of spores was determined by measuring 20 germ tubes at random on each cover glass. All experiments were conducted four times on different dates. For each experiment, regression curves were fitted to the values of germination rate and germ tube length versus temperature using Statistix 8 (Analytical Software, Tallahassee, FL). Optimum temperatures for germination and germ tube length were calculated from the best adjusted model. Analysis of variance and orthogonal contrasts were used to compare fitted maximum values of germination rate and germ tube length of two conidial and one ascosporic isolates using experiments as blocks. The same analysis was applied to the area under curves of germination rate and germ tube length over temperature.

Effect of water potential on spore germination and germ tube elongation. The agar isopiestic equilibration technique originally described by Harris et al. (8) and modified by Alderman and Beute (1) was used to control RH. Details of the modified technique used by Arauz and Sutton (2) are as follows: microscope cover glasses coated with WA were dried in an oven at $110^{\circ} \mathrm{C}$ for $24 \mathrm{~h}$. Dried cover glasses with air-dried drops of conidial suspensions or discharged ascospores were placed between hydrated 9-cm-diameter WA slabs located on the top and bottom of 9-cm-diameter petri dishes. The air space between the two agar slabs was less than $2 \mathrm{~mm}$. To achieve the various $\mathrm{RH}$ levels, the osmotic potential of the WA was adjusted to $0,-2,-4$, -6 , or $-8 \mathrm{MPa}$ (which corresponds to $100,98.5,97.1,95.7$, and 94.3\% $\mathrm{RH}$, respectively, at $20^{\circ} \mathrm{C}$ ) using $\mathrm{NaCl}$ (20). Dishes were sealed with Parafilm (American National Can, Neenah, WI) and incubated at $0,5,10,15,20,25,30$, and $35^{\circ} \mathrm{C}$. The concentration of $\mathrm{NaCl}$ was adjusted to provide similar water potentials at each temperature. After $18 \mathrm{~h}$ of incubation, ascospores and conidia were stained with acid fuchsin in lactophenol and germination and germ tube growth were assessed. The experiment was repeated twice. At the calculated optimal temperature for spore germination $\left(20^{\circ} \mathrm{C}\right)$, regression lines were fitted to the logarithmic values of germination rate and germ tube length versus water potential and comparison among regression lines was performed using Statistix 8 Software (Analytical Software).

Comparative pathogenicity of ascospores and conidia. All inoculations were performed with 2-week-old chickpea seedlings of cultivar Burpee (PI 458770) that had five to seven leaves. Procedures for handling plants and conidial inoculum have been described (24). For inoculation with ascospores, two methods were compared. In both, pieces of naturally infested chickpea stem debris with large numbers of mature pseudothecia of D. rabiei were the source of ascospores. Stem pieces were soaked in deionized water for about $30 \mathrm{~min}$, blotted dry with paper towels, and placed on a wire screen $(10 \mathrm{~mm}$ mesh). Wet paper towels were placed over the stem pieces to keep them moist.

In the first method, ascospores were discharged directly onto the chickpea seedlings by placing the wire screen about $40 \mathrm{~cm}$ above healthy potted plants in plastic moist chambers. The plants were placed in metal trays partially filled with water. The moist chambers were then put in darkened controlled growth chambers (Controlled Environments, Winnipeg, Canada) at $20^{\circ} \mathrm{C}$. Plants were exposed to inoculum for $48 \mathrm{~h}$. The range of ascospore deposition density measured on microscope slides placed at the level of the plant leaves was 100 to 500 ascospores per $\mathrm{cm}^{2}$.

In the second method, ascospores were discharged into water and Burpee chickpea seedlings were sprayed with the ascospore suspension using an airbrush sprayer (Paasche Airbrush Co., Harwood Heights, IL). To obtain a concentrated ascospore suspension, heavily infested chickpea stems were placed close together on a wire screen in a plastic moist chamber and ascospores were discharged overnight into a tray or glass bowl containing a thin layer of sterile distilled water. The collection container was placed on ice to prevent ascospores from germinating. The suspension was adjusted with sterile distilled water to $2 \times 10^{4}$ ascospores per $\mathrm{ml}$ with a hemacytometer. The same concentration of conidia was prepared from a 6-day-old monoascosporic culture of the pathogen grown on CDA. The monoascosporic isolate (AR 8621, MAT1-2) was obtained from the same infested chickpea stem pieces that were used to obtain ascospores. Tween 20 (1 drop per $100 \mathrm{ml}$ ) was added to the spore suspensions as a wetting agent. Inoculated seedlings were incubated in the moist chambers in darkened growth chambers at $20^{\circ} \mathrm{C}$ for $48 \mathrm{~h}$.

In both methods, upon removal from the growth chambers, the plants were dried for about $30 \mathrm{~min}$ using a fan, and transferred to the greenhouse $\left(18\right.$ to $26^{\circ} \mathrm{C}$ ) for symptom development. Besides incubation in the greenhouse, chickpea plants were incubated in a controlled chamber at $20^{\circ} \mathrm{C}$ to compare the inoculation methods at that temperature. Both incubation treatments were applied to three replicated pots, each with three Burpee chickpea seedlings. Disease severity was assessed weekly using a 0 to 9 rating scale $(0=$ healthy plant, $9=$ dead plant $)$ and values were converted into percentage of foliage affected $(0=0 \%, 1=2.5 \%, 2=5 \%, 3=$ $10 \%, 4=20 \%, 5=40 \%, 6=60 \%, 7=80 \%, 8=95 \%$, and $9=$ $100 \%$ ) (24). The experiment was conducted twice. Percentage values were transformed into arcsine $\sqrt{S_{i} / 100}$ for analysis of variance. After a general analysis using the two experiment repetitions as blocks, separate analysis of variance and orthogonal contrasts for disease severity were performed on each incubation treatment at 7 and 14 days after inoculation.

The first inoculation method was also used to test the pathogenicity of ascospores on chickpea cultivars Blanco Lechoso, Burpee, Pedrosillano, and ILC 3279. Cultivars Burpee and Blanco Lechoso are very susceptible, Pedrosillano is moderately suscep- 
tible, and ILC 3279 is resistant to A. rabiei (24). There were three replicated pots, each with three seedlings of each cultivar. The experiment was replicated twice.

Effect of temperature on infection and disease development. The second inoculation method described above was used to compare the ability of ascospores and conidia to infect Burpee chickpea at different temperatures. Detailed procedures for handling conidial inoculum and inoculating chickpeas have been described (24). Plants were sprayed to runoff ( $1 \mathrm{ml}$ per seedling) with the spore suspension $\left(2 \times 10^{4}\right.$ ascospores or conidia per $\left.\mathrm{ml}\right)$ and incubated for $48 \mathrm{~h}$ for each wetness period inside plastic moist chambers that were placed in darkened environmental chambers set at $5,10,15,20,25$, and $30^{\circ} \mathrm{C}$. After the wetting period, plants were removed from the plastic cages, dried, and returned to the same environmental chambers with a 14-h light period or to the greenhouse at 18 to $26^{\circ} \mathrm{C}$ for symptom development. Disease severity was assessed weekly using the 0 to 9 rating scale (24). Final assessments were made when disease severity reached the maximum value, or started to decline at each temperature. This was approximately 14 to 21 days at 15 to $20^{\circ} \mathrm{C}$. At 5 and $10^{\circ} \mathrm{C}$, final assessments were made 35 and 28 days after inoculation, respectively.

Each combination of temperature and spore type included three replicated pots, each with three seedlings, and the experiment was conducted twice. A third repetition of the experiment was performed using an ascospore suspension kept in the freezer $\left(-18^{\circ} \mathrm{C}\right)$ for 1 week. A randomized complete block design was applied to the pooled arcsine-transformed percentage data using the three repetitions of the experiment as blocks. Analysis of variance and orthogonal contrasts were performed using Statistix 8.
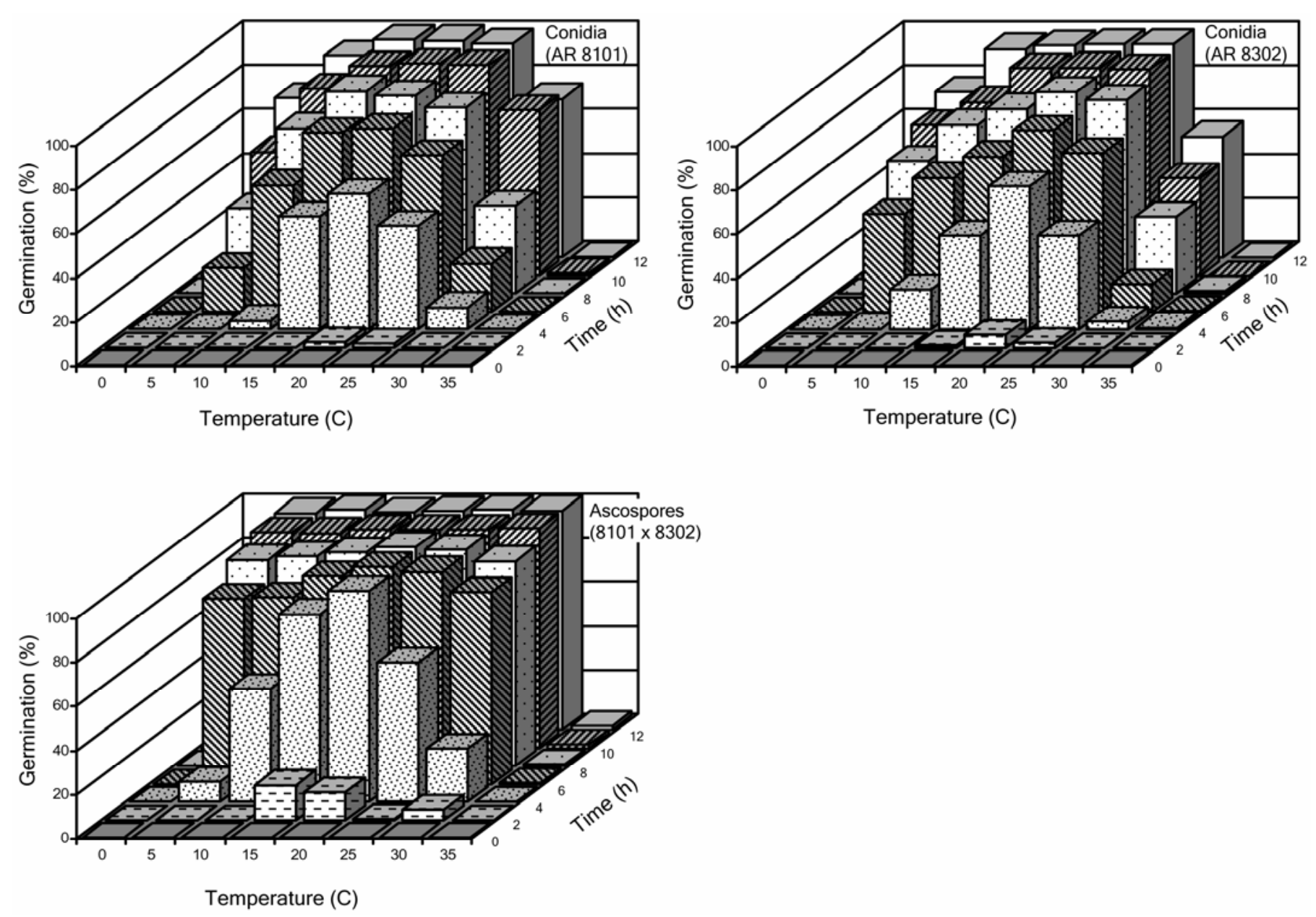

Fig. 1. Effect of temperature and time on germination of conidia (isolates AR 8101 and AR 8302) and ascospores (cross between AR 8101 and AR 8302 ) of Didymella rabiei. Only data for the first $12 \mathrm{~h}$ are presented.
Effect of wetness periods on infection and disease development. Chickpea seedlings were sprayed with a spore suspension $\left(2 \times 10^{4}\right.$ ascospores or conidia per $\left.\mathrm{ml}\right)$ and then were subjected to one of three wet-dry treatments: (i) a continuous wetness period of 6-, 12-, 24-, or 48-h and the 0-h wetness check, (ii) a 24-h wetness period after a 6-, 12-, 24-, or 48-h dry period initiated immediately after inoculation, and (iii) a 24-h interrupted wetness period with 6-h wetness immediately after inoculation and the other 18-h wetness after a dry period of $6,12,24$, and $48 \mathrm{~h}$. Procedures for handling plants, inoculation, and wet-dry treatments have been described (24). During the wetness period, plants were incubated in the moist chambers in a darkened growth chamber at $20^{\circ} \mathrm{C}$ with $\mathrm{RH}>75 \%$. For the dry treatment, plants were dried with a cool air flow from a hair drier and incubated in a growth chamber at $20^{\circ} \mathrm{C}$ with a 14 -h photoperiod and $\mathrm{RH}$ $<50 \%$. Dried plants were rewetted by spraying the foliage with a fine mist of water and placing them in the moist chambers. Temperature and RH were monitored continuously with a hygrothermograph (Belfort Instruments, Baltimore, MD). After the last wetness period, plants were dried and incubated in the dry growth chamber mentioned above for a postinoculation period of 7 days. Plants were transferred to the greenhouse at 18 to $26^{\circ} \mathrm{C}$ for symptom development. Disease severity was recorded 14 days after inoculation using the 0 to 9 rating scale and values were converted into percentage of foliage affected (24). Each treatment included three replicated pots, each with three seedlings, and the experiment was replicated twice. Analysis of variance and LSD test $(P=$ $0.05)$ were performed on the pooled arcsine-transformed data from the two experiments, using wetness/dry treatments as a factor with 13 levels, and the two repetitions of the experiment as blocks. 


\section{RESULTS}

Effect of temperature on spore germination and germ tube growth. Germination of ascospores and conidia of D. rabiei on cover glasses coated with WA began $2 \mathrm{~h}$ after the postinoculation dew periods and was $>95 \%$ at temperatures between 5 and $30^{\circ} \mathrm{C}$ within 6 to $32 \mathrm{~h}$. Spores did not germinate at 0 and $35^{\circ} \mathrm{C}$ (Fig. 1). Morphology of germ tubes was similar at all temperatures tested, except at $30^{\circ} \mathrm{C}$ where they were thickened and distorted. At $35^{\circ} \mathrm{C}$, ungerminated ascospores were deformed. Although maximum germination occurred at all temperatures after 12- to 24-h incubation, the MGT, or its inverse the GR, varied greatly with temperature (Fig. 2). At the optimum temperature, which was $20^{\circ} \mathrm{C}$, GR/MGT of the conidial isolates AR 8101 and AR 8302 and the ascosporic isolate were $0.27 / 3.7,0.28 / 3.5$, and $0.35 / 2.8 \mathrm{~h}^{-1} / \mathrm{h}$, respectively (Fig. 2). Ascospores germinated more rapidly than conidia at all temperatures (Figs. 1 and 2). Germ tubes of ascospores were longer than those of conidia, and maximum length was obtained at $20^{\circ} \mathrm{C}$. After $12 \mathrm{~h}$ at $20^{\circ} \mathrm{C}$, ascospore germ tubes had a mean length of $72 \mu \mathrm{m}$, whereas the mean length of conidial germ tubes was $42 \mu \mathrm{m}$ (Fig. 2). The best regression model for germination rate and germ tube length data was a third-degree polynomial model: $Y=a T^{3}+b T$, in which $Y=$ germination rate or germ tube length, $T=$ temperature, and $a$ and $b$ are the regression coefficients (Tables 1 and 2). Analysis of variance and orthogonal contrasts showed no differences among isolates for the optimum temperature which was $20^{\circ} \mathrm{C}$. However, they showed significant differences between the ascosporic isolate and the two conidial isolates, and no differences between the conidial isolates, for the rest of the variables tested, maximum germination rate, maximum germ tube length, and area under germination rate or germ tube length over temperature (Tables 1 and 2).

Effect of humidity on spore germination and germ tube elongation. Germination of ascospores and conidia at $100 \% \mathrm{RH}$ was somewhat delayed compared to that observed on WA, but it declined rapidly as water potential was reduced from 0 to -4
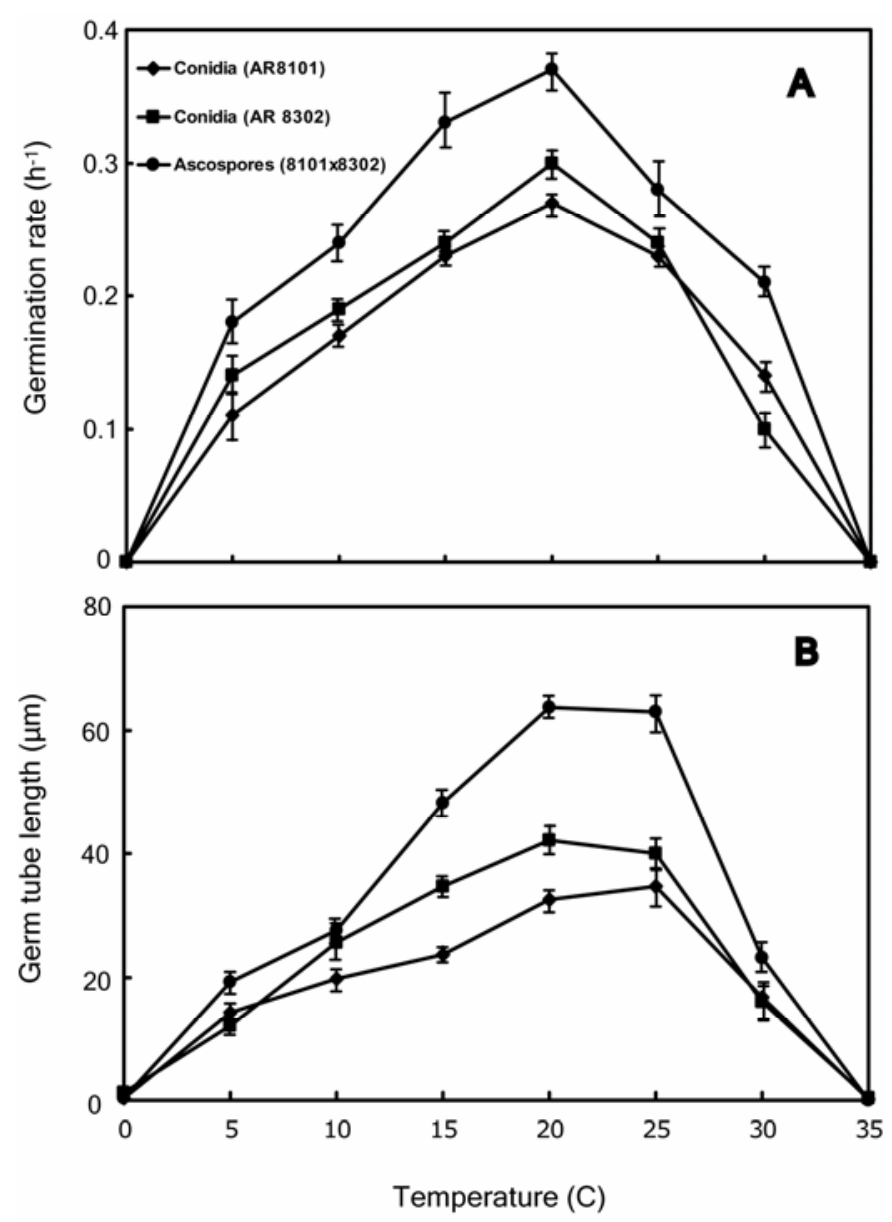

Fig. 2. A, Effect of temperature on germination rate and $\mathbf{B}$, germ tube length of ascospores and conidia of Didymella rabiei on water agar after $12 \mathrm{~h}$. Bars represent the standard error of the mean.

TABLE 1. Effect of temperature on germination rate of ascospores and conidia of Didymella rabiei

\begin{tabular}{|c|c|c|c|c|c|c|}
\hline \multirow[b]{2}{*}{ Isolate $^{v}$} & \multicolumn{3}{|c|}{ Adjusted model $^{\mathrm{w}}$} & \multirow{2}{*}{$\begin{array}{c}\text { Optimal } \\
\text { temperature }\left({ }^{\circ} \mathrm{C}\right)^{\mathrm{x}}\end{array}$} & \multirow{2}{*}{$\begin{array}{c}\text { Maximum } \\
\text { germination rate }\left(\mathrm{h}^{-1}\right)^{\mathrm{x}}\end{array}$} & \multirow[b]{2}{*}{$\mathrm{AUC}^{\mathrm{y}}$} \\
\hline & $R^{2}$ & $a\left(\times 10^{-4}\right)$ & $b\left(\times 10^{-2}\right)$ & & & \\
\hline AR 8101 (1) & 0.958 & -0.162 & 1.96 & $20.1 \mathrm{a}^{\mathrm{z}}$ & $0.26 \mathrm{~b}$ & $5.86 \mathrm{~b}$ \\
\hline AR 8302 (2) & 0.935 & -0.174 & 2.05 & $19.8 \mathrm{a}$ & $0.27 \mathrm{~b}$ & $6.00 \mathrm{~b}$ \\
\hline
\end{tabular}

$\mathrm{v}$ Two conidial isolates (AR 8101 and AR 8302) and one ascosporic isolate (cross between AR 8101 and AR 8302) were used.

${ }^{\mathrm{w}}$ Germination rate (GR), calculated as the inverse of mean germination time (MGT), was adjusted to a third-degree polynomial model: $Y=a T^{3}+b T$, in which $Y=$ germination rate, $a$ and $b$ are the regression coefficients and $R^{2}=$ coefficient of determination.

$x$ Estimated by the adjusted model.

y Area under the curve of germination rate over temperature (Fig. 2A).

${ }^{\mathrm{z}}$ Data are the average of four experiments with 60 spores per each temperature and time period. In each experiment, mean values were estimated by the adjusted model and analysis of variance was applied to them using the four repetitions of the experiment as blocks. For each column, means with the same letter are not significantly different according to orthogonal contrasts test $(P=0.05)$.

TABLE 2. Effect of temperature on length of germ tubes of ascospores and conidia of Didymella rabiei

\begin{tabular}{|c|c|c|c|c|c|c|}
\hline \multirow[b]{2}{*}{ Isolate $^{v}$} & \multicolumn{3}{|c|}{ Adjusted model $^{\mathrm{w}}$} & \multirow{2}{*}{$\begin{array}{c}\text { Optimal } \\
\text { temperature }\left({ }^{\circ} \mathrm{C}\right)^{\mathrm{x}}\end{array}$} & \multirow{2}{*}{$\begin{array}{l}\text { Maximum germ } \\
\text { tube length }(\mu \mathrm{m})^{\mathrm{x}}\end{array}$} & \multirow[b]{2}{*}{$\mathrm{AUC}^{\mathrm{y}}$} \\
\hline & $R^{2}$ & $a\left(\times 10^{-4}\right)$ & $b\left(\times 10^{-2}\right)$ & & & \\
\hline AR 8101 (1) & 0.948 & -0.936 & 1.16 & $20.3 \mathrm{a}$ & $39.3 b^{z}$ & $352.5 b^{2}$ \\
\hline AR 8302 (2) & 0.914 & -1.230 & 1.48 & $20.0 \mathrm{a}$ & $49.3 \mathrm{~b}$ & $430.7 \mathrm{~b}$ \\
\hline
\end{tabular}

${ }^{v}$ Two conidial isolates (AR 8101 and AR 8302) and one ascosporic isolate (cross between AR 8101 and AR 8302) were used.

${ }^{\text {w }}$ Germination tube length was adjusted to a third-degree polynomial model: $Y=a T^{3}+b T$, in which $Y=$ germination rate, $a$ and $b$ are the regression coefficients, and $R^{2}=$ coefficient of determination.

${ }^{\mathrm{x}}$ Estimated by the adjusted model.

y Area under the curve of germ tube length over temperature (Fig. 2B).

${ }^{\mathrm{z}}$ Data are the average of four experiments with 20 spores per each temperature and time period. In each experiment, mean values were estimated by the adjusted model and analysis of variance was applied to them using the four repetitions of the experiment as blocks. For each column, means with the same letter are not significantly different according to orthogonal contrasts test $(P=0.05)$. 

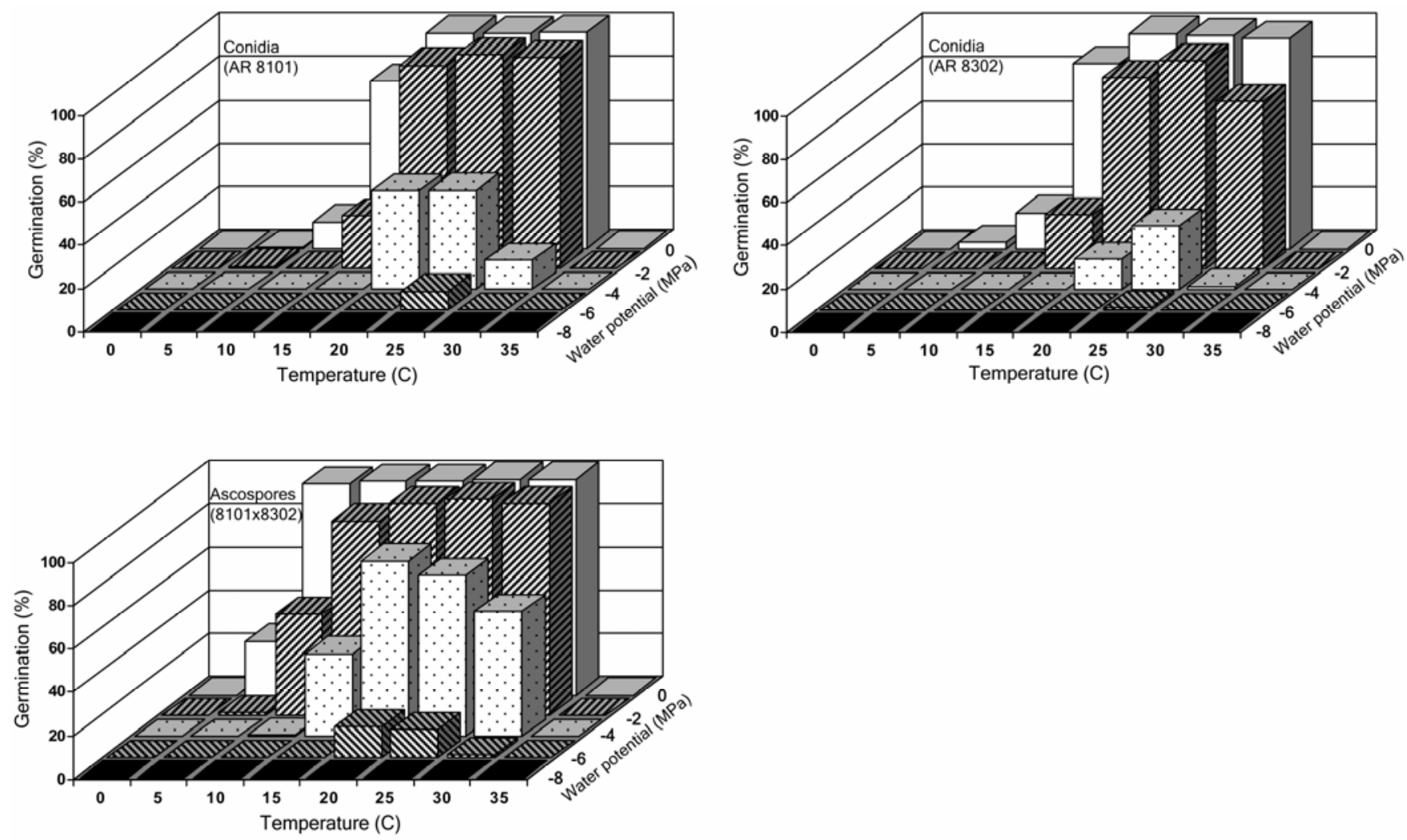

Fig. 3. Effect of temperature and water potential on germination of conidia (isolates AR 8101 and AR 8302) and ascospores (cross between AR 8101 and AR 8302 ) of Didymella rabiei after $18 \mathrm{~h}$. Water potentials of $0,-2,-4,-6$, and $-8 \mathrm{MPa}$ correspond to $100,98.5,97.1,95.7$, and $94.3 \%$ relative humidity, respectively, at $20^{\circ} \mathrm{C}$.
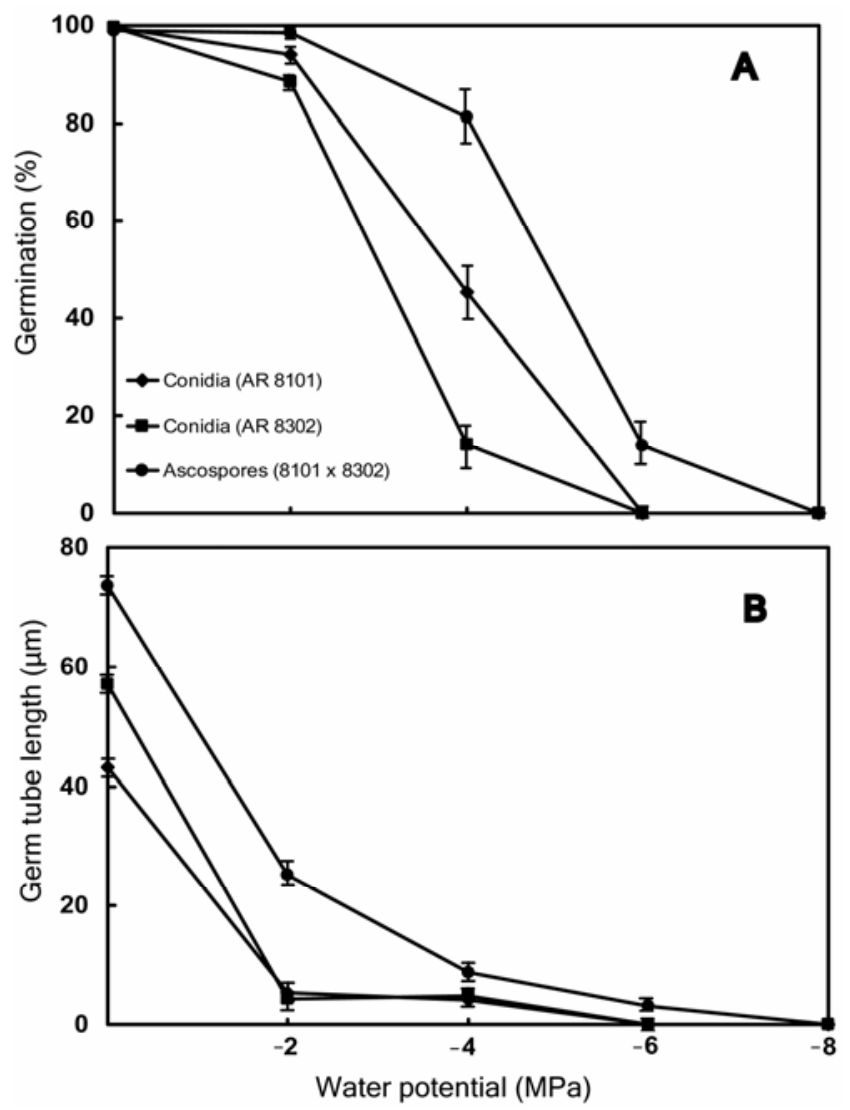

Fig. 4. A, Effect of water potential on germination and $\mathbf{B}$, germ tube length of ascospores and conidia of Didymella rabiei after $18 \mathrm{~h}$ at $20^{\circ} \mathrm{C}$. Water potentials of $0,-2,-4,-6$, and $-8 \mathrm{MPa}$ correspond to $100,98.5,97.1,95.7$, and $94.3 \%$ relative humidity, respectively, at $20^{\circ} \mathrm{C}$. Bars represent the standard error of the mean. (approximately from 100 to $97 \% \mathrm{RH}$ ), and this effect depended on temperature (Fig. 3). After $18 \mathrm{~h}$ at $-6 \mathrm{MPa}$, only 13 to $14 \%$ of the ascospores, and 0 to $8 \%$ and $0 \%$ of the conidia of isolates $\mathrm{AR}$ 8101 and AR 8302 , respectively, germinated at 20 to $25^{\circ} \mathrm{C}$, and none germinated at the other temperatures. No germination occurred at $-8 \mathrm{MPa}$ or lower (Fig. 3). The greatest germination at different water potentials occurred at 20 to $25^{\circ} \mathrm{C}$. Ascospores germinated over a wider range of RH than conidia. After $18 \mathrm{~h}$ at $20^{\circ} \mathrm{C}$, ascospore germ tubes reached a mean length of $74 \mu \mathrm{m}$, whereas that of conidia was $50 \mu \mathrm{m}$ (Fig. 4). Comparison of regression lines for germination and germ tube length of three isolates over water potential at $20^{\circ} \mathrm{C}$ showed significant differences $(P=0.05)$ for elevations but not for slopes (Table 3 ). Ascospores showed a higher germination level and developed longer germ tubes than conidia, over all water potentials. The two conidial isolates did not differ in their temperature and relative humidity requirements for germination and germ tube growth.

Effect of inoculation method with ascospores and conidia on infection. The method of inoculating chickpea seedlings with ascospores and conidia of $D$. rabiei markedly affected severity of disease, 7 and 14 days after inoculation (Table 4). Disease was most severe on chickpeas inoculated with ascospores that were discharged directly onto plants from naturally infested chickpea debris, and after 14 days of incubation, all plants were dead. Disease severity on plants inoculated with ascospores that were sprayed on the foliage was significantly less than that of ascospores discharged directly onto the foliage. However, it was significantly higher than that of conidial suspensions sprayed on the foliage, 7 and 14 days after inoculation. Considering the evaluation dates together, disease severity was invariably higher on inoculated plants incubated in environmental chambers at $20^{\circ} \mathrm{C}$ than in the greenhouse where temperatures varied from 18 to $26^{\circ} \mathrm{C}$ (Table 4). Ascospores were highly infective on blight-susceptible chickpea cultivars. Chickpea cultivars showed a variable 
TABLE 3. Comparison of regression lines of germination and germ tube length of Didymella rabiei over water potential ${ }^{\mathrm{x}}$

\begin{tabular}{|c|c|c|c|c|c|c|}
\hline \multirow[b]{2}{*}{ Isolate $^{y}$} & \multicolumn{3}{|c|}{ Regression line for germination $(\%)$} & \multicolumn{3}{|c|}{ Regression line for germ tube length $(\mu \mathrm{m})$} \\
\hline & $R^{2}$ & $a$ & $b$ & $R$ & $a$ & $b$ \\
\hline AR 8101 (1) & 0.883 & $-0.32 \mathrm{a}^{\mathrm{z}}$ & $0.26 \mathrm{a}$ & 0.914 & $0.25 \mathrm{a}$ & $1.48 \mathrm{~b}$ \\
\hline AR 8302 (2) & 0.886 & $-0.32 \mathrm{a}$ & $0.33 \mathrm{a}$ & 0.826 & $0.26 \mathrm{a}$ & $1.53 \mathrm{~b}$ \\
\hline Ascospores $(1 \times 2)$ & 0.843 & $-0.31 \mathrm{a}$ & $0.69 \mathrm{~b}$ & 0.997 & $0.25 \mathrm{a}$ & $1.89 \mathrm{a}$ \\
\hline
\end{tabular}

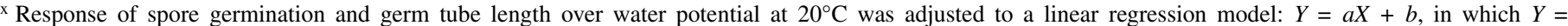
germinated spores $(\%)$ or germ tube length $(\mu \mathrm{m}), X=$ water potential $(\mathrm{MPa}), R^{2}=$ coefficient of determination, $a=$ slope, and $b=$ elevation

y Two conidial isolates (AR 8101 and AR 8302) and one ascosporic isolate (cross between AR 8101 and AR 8302) were used.

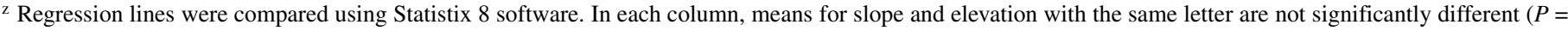
$0.05)$.

TABLE 4. Effect of three inoculation methods and two incubation treatments on infection of chickpea by ascospores and conidia of Didymella rabiei

\begin{tabular}{|c|c|c|c|c|}
\hline \multirow[b]{3}{*}{ Inoculation method ${ }^{\mathrm{x}, \mathrm{y}}$} & \multicolumn{4}{|c|}{ Disease severity $(\%)^{\mathrm{z}}$} \\
\hline & \multicolumn{2}{|c|}{$\begin{array}{c}\text { Growth chamber } \\
\text { days after inoculation }\end{array}$} & \multicolumn{2}{|c|}{$\begin{array}{c}\text { Greenhouse } \\
\text { days after inoculation }\end{array}$} \\
\hline & 7 & 14 & 7 & 14 \\
\hline A & $88.3 \mathrm{a}$ & $100.0 \mathrm{a}$ & $65.0 \mathrm{a}$ & $100.0 \mathrm{a}$ \\
\hline B & $32.2 \mathrm{~b}$ & $75.0 \mathrm{~b}$ & $23.6 \mathrm{~b}$ & $49.4 \mathrm{~b}$ \\
\hline $\mathrm{C}$ & $10.3 \mathrm{c}$ & $50.8 \mathrm{c}$ & $11.4 \mathrm{c}$ & $35.4 \mathrm{c}$ \\
\hline
\end{tabular}

${ }^{\mathrm{x}} \mathrm{A}=$ ascospores were discharged directly from infested chickpea straw onto chickpea seedlings; $\mathrm{B}=$ chickpea seedlings sprayed with an ascospore suspension $\left(2 \times 10^{4}\right.$ ascospores per $\left.\mathrm{ml}\right) ; \mathrm{C}=$ chickpea seedlings sprayed with a conidial suspension $\left(2 \times 10^{4}\right.$ conidia per $\left.\mathrm{ml}\right)$. The range of spore deposition density measured on microscope slides placed at the level of plant leaves was similar ( 100 to 500 spores per $\mathrm{cm}^{2}$ ) in the three inoculation methods.

${ }^{y}$ Inoculated plants were incubated in plastic moist chambers in a growth chamber at $20^{\circ} \mathrm{C}$ or in a greenhouse at 18 to $26^{\circ} \mathrm{C}$. After a $48 \mathrm{~h}$ period of wetness in the dark, plants were removed from the moist chambers, dried, and maintained under light (14-h photoperiod) in the growth chamber or in the greenhouse with the same day length for symptom development.

${ }^{z}$ Disease severity was assessed at 7 and 14 days after inoculation using a 0 to 9 rating scale $(0=$ healthy plant, $9=$ dead plant) and values were converted into percentage of foliage affected. Data are the average of two experiments with three replicated pots, each with three plants. In each column, means with the same letter are not significantly different according to analysis of variance and orthogonal contrasts test $(P=0.05)$.

degree of susceptibility to the disease. On the scale 0 to 9 , mean disease severity 30 days after inoculation was 9 for cultivars Blanco Lechoso and Burpee, 5 to 6 for Pedrosillano, and 2 to 3 for ILC 3279 (data not shown).

Effect of temperature on infection and disease development. The optimum temperature for infection of, and disease development on plants inoculated with ascospores and conidia was $20^{\circ} \mathrm{C}$ (Fig. 5). Disease severity was influenced by incubation conditions. After a 48-h infection period at different constant temperatures of $5,10,15,20,25$, and $30^{\circ} \mathrm{C}$ in the growth chambers, plants moved to the greenhouse showed disease symptoms over a wider range of temperatures than those that were maintained in the growth chambers. Inoculation with ascospores resulted in a significantly higher disease severity in all plants incubated in the greenhouse and in plants incubated in the growth chambers for temperatures lower than $25^{\circ} \mathrm{C}$. Interaction between temperature and inoculum type was significant only for plants incubated in growth chambers, since the disease severity caused by ascospore inoculum did not differ significantly from that caused by conidial inoculum at $25^{\circ} \mathrm{C}$ (Fig. 5). For both types of inoculum, characteristic lesions with pycnidia developed in all treatments at temperatures between 10 and $25^{\circ} \mathrm{C}$, and at 5 and $30^{\circ} \mathrm{C}$ in plants exposed to these temperatures only during the wetness period $(48 \mathrm{~h})$ and then incubated in the greenhouse. In the growth chamber, plants exposed to 5 and $30^{\circ} \mathrm{C}$ during the entire experiment did not develop visible lesions (Fig. 5), but they were infected since the pathogen was isolated from stem and leaf samples.
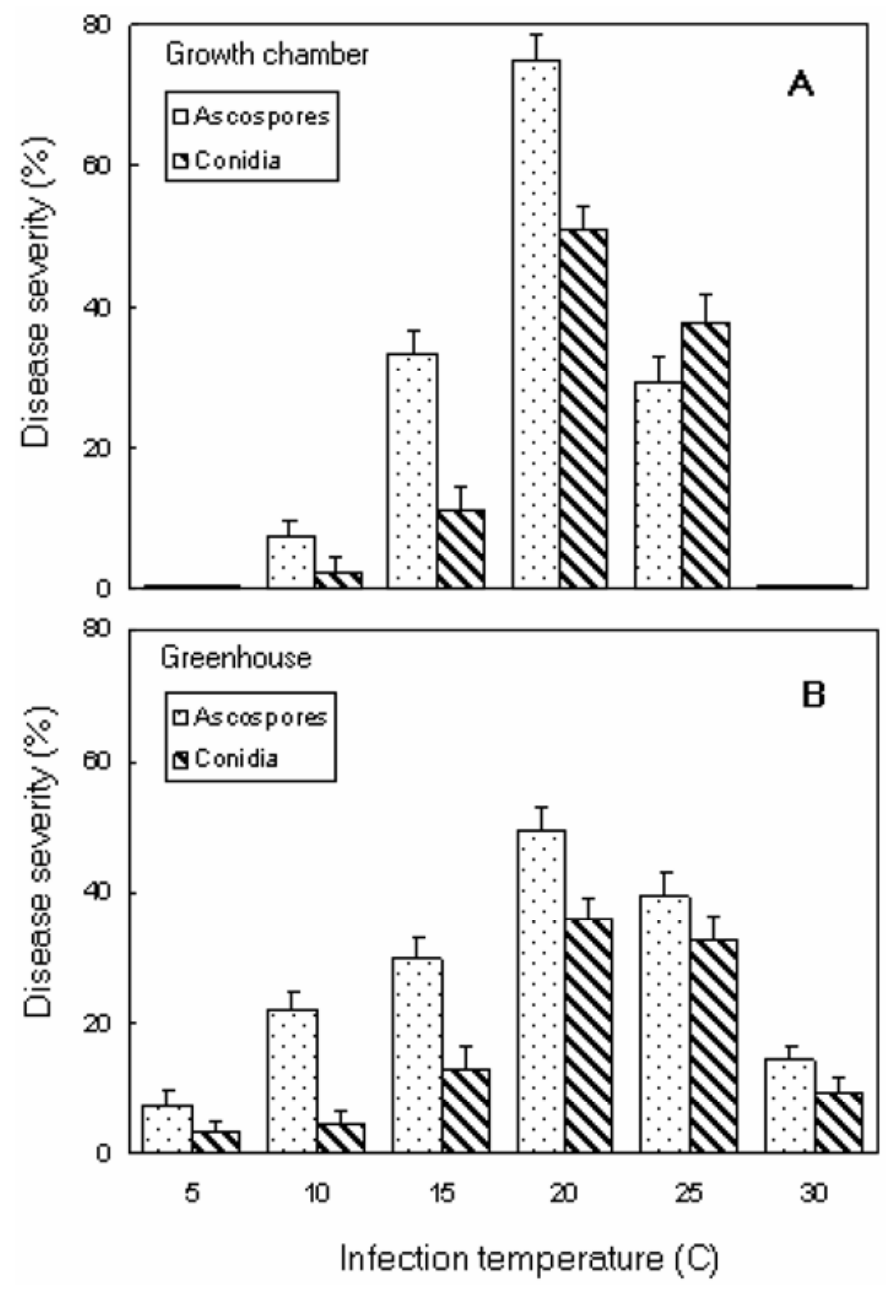

Fig. 5. Effect of temperature on disease severity on 2-week-old chickpea seedlings inoculated with ascospores or conidia (isolate AR 8621) of Didymella rabiei. Inoculated plants were placed in a growth chamber at 5, 10, 15, 20, 25, and $30^{\circ} \mathrm{C}$. After a 48 -h wetness period in the dark, $\mathbf{A}$, plants were dried and then replaced in the same growth chambers at the same temperatures with a 14-h photoperiod, or $\mathbf{B}$, placed in the greenhouse at 18 to $26^{\circ} \mathrm{C}$ with 14 -h day length Values are the mean of three experiments with three replicated pots, each with three seedlings. Bars represent the standard error of the mean.

Effect of wetness periods on infection and disease development. Disease severity of chickpea plants receiving a wetness period of $0,6,12,24$, or $48 \mathrm{~h}$ immediately after inoculation increased with longer wetness periods (Table 5). Plants inoculated with ascospores had a higher disease severity rating than those inoculated with conidia. The inclusion of a variable dry period immediately or $6 \mathrm{~h}$ after inoculation greatly influenced disease severity and there were not differences between both types of inoculum. The effect of drying depended on the timing and length of wetness period interruptions (Table 5). When the dry period be- 
gan immediately after inoculation, disease severity in plants inoculated with ascospores or conidia increased significantly for the shorter dry periods compared with the same wetness period $(24 \mathrm{~h})$ without interruption. However, disease severity in plants inoculated with both types of inoculum decreased at the longer dry periods (Table 5). When the dry period began $6 \mathrm{~h}$ after inoculation, the highest disease severity was 18.6 and $15.8 \%$ for the ascospore and conidial inoculum, respectively, and was not significantly different from the disease severity for the 24-h period of continuous wetting after inoculation. However, when the duration of the dry period was increased from 6 to $48 \mathrm{~h}$, there was a significant reduction in disease severity from 18.6 to $5.0 \%$ for the ascospore inoculum and from 15.8 to $4.3 \%$ for the conidial inoculum (Table 5).

\section{DISCUSSION}

Until the present study, little or no information was available on the effects of temperature and relative humidity on germination and germ tube growth of ascospores and conidia of D. rabiei. Both spore types are important in the epidemiology of Ascochyta blight by providing the primary and secondary inoculum required for disease development and spread $(25,26)$. Both propagules germinated over a wide range of temperatures. The optimum temperature for mycelial growth of the pathogen is around $20^{\circ} \mathrm{C}(11,15,19,28)$, which is similar to that for germination of ascospores and conidia. Germination of ascospores and conidia occurred rapidly, beginning in $2 \mathrm{~h}$ at favorable temperatures, and was more than $95 \%$ within 6 to $7 \mathrm{~h}$ at 15 to $25^{\circ} \mathrm{C}$. The speed of spore germination may be one of the important factors contributing to the explosive development of blight epidemics when environmental conditions are highly conducive to disease development and spread. Additionally, ascospores germinated more rapidly than conidia and germ tube growth was faster for ascospores at all temperatures tested. This phenomenon has also been observed in other plant pathogenic ascomycetous fungi $(3,23)$. The germination rate (inverse of MGT) of ascospores of $D$. rabiei was significantly faster at all temperatures tested as compared with that of conidia of two isolates of the pathogen.

TABLE 5. Effect of wetness duration and interrupted wetness period on disease severity in chickpea plants inoculated with ascospores or conidia of Didymella rabiei ${ }^{\mathrm{w}}$

\begin{tabular}{cccccc}
\hline \multicolumn{3}{c}{ Postinoculation treatments $(\mathrm{h})^{\mathrm{x}}$} & & \multicolumn{2}{c}{ Disease severity $(\%)^{\mathrm{y}}$} \\
\cline { 1 - 2 } \cline { 5 - 6 } Wet & Dry & Wet & & Ascospores & Conidia \\
\hline 0 & - & - & & 0.3 & 0.5 \\
6 & - & - & & 4.9 & 2.5 \\
12 & - & - & & 7.5 & 5.3 \\
24 & - & - & & 19.6 & 12.7 \\
48 & - & - & & 38.3 & 29.6 \\
- & 6 & 24 & & 40.0 & 56.3 \\
- & 12 & 24 & & 33.3 & - \\
- & 24 & 24 & & 16.7 & - \\
- & 48 & 24 & & 12.7 & 23.7 \\
6 & 6 & 18 & & 18.6 & 15.8 \\
6 & 12 & 18 & & 13.8 & - \\
6 & 24 & 18 & & 9.8 & - \\
6 & 48 & 18 & & 5.0 & 4.3 \\
& LSD $^{\mathrm{z}}(P=0.05)$ & & & 6.2 & 5.1 \\
\hline
\end{tabular}

w Two-week-old seedlings of chickpea cultivar Burpee were inoculated with $2 \times 10^{4}$ ascospores or conidia per $\mathrm{ml}$ of D. rabiei, incubated at constant $20^{\circ} \mathrm{C}$ for 1 week and then in the greenhouse at 18 to $26^{\circ} \mathrm{C}$.

${ }^{x}$ For the first or second wet periods, plants were incubated immediately after inoculation or after the dry period, respectively, in a saturated atmosphere in an environmental chamber. After the respective wet period, plants were dried, and incubated in an environmental chamber with less than $50 \%$ relative humidity.

y Disease severity was assessed at 14 days after inoculation using a 0 to 9 rating scale $(0=$ healthy plant, $9=$ dead plant $)$ and the values were converted into the percentage of foliage affected. Data are the average of two experiments with three replicated pots, each with three plants.

${ }^{\mathrm{z}} \mathrm{LSD}=$ Fisher's protected least significant difference.
Relative humidity, expressed as water potential, had a profound effect on germination and germ tube growth of ascospores and conidia of D. rabiei. At lower RH, germination was lower, and it was null at $-8 \mathrm{MPa}$ (approximately $94 \% \mathrm{RH}$ ). Ascospores germinated over a wider range of water potential and germ tube growth of them was also larger than that of conidia at -6 to $0 \mathrm{MPa}$. The ability of conidia, and especially ascospores, to germinate at lower RH would aid in extending the length of the germination period after the end of a wetting period and may be important in determining whether or not infection conditions have been met.

Isolates of $A$. rabiei differ greatly in cultural characteristics and pathogenicity $(11,13,15,19,22,28)$. We have demonstrated that the two types of spores (ascospores and conidia) of the pathogen also differ in their temperature and relative humidity requirements for germination and germ tube growth. Additional studies are needed to determine how large and widespread these differences are among isolates of $A$. rabiei and how these differences may affect infection and disease development.

Disease severity following discharge of ascospores from naturally infested chickpea debris, directly onto chickpea plants, was significantly larger than that caused by applying aqueous suspensions of ascospores and conidia onto plants. Since the density of ascospore inoculum discharged onto the foliage was similar to that sprayed onto the plants, the higher disease incidence observed in this treatment may have resulted from a better spore deposition in direct aerial inoculations than when plants were inoculated with ascospores and conidia in water suspensions. Moreover, one or more chemical compounds or substances may be present on or attached to the surface of ascospores of $D$. rabiei when they are discharged onto a plant surface, or they are secreted by the ascospores during germination (17). These products assist in the protection and/or attachment of the spores to the leaf surface, but are absent or partially removed when the spores are suspended in water before inoculation (10). A mucilaginous matrix is present around conidia of some fungi, like Mycosphaerella pinodes, which may assist in attachment, germination, protection, and/or survival of the spores $(5,16,17)$. Removal of the gelatinous matrix may adversely affect the longevity of the spores. Most studies on attachment of spores to the host surface have dealt with conidia and few with the ascospores of pathogenic fungi $(5,10,16,17)$. The adherence of abundant ascospore inoculum to the surface of the chickpea foliage might enable the fungus to germinate and infect the foliar tissues more quickly and efficiently than spores sprayed on the foliage.

Trapero-Casas and Kaiser (24) reported that only a few infections occurred on inoculated chickpea plants in the absence of a wetness period. Similarly, dry periods up to $48 \mathrm{~h}$ that began immediately after inoculation, or dry periods up to $12 \mathrm{~h}$ that began $6 \mathrm{~h}$ after inoculation, did not affect infection. Ungerminated conidia of $A$. rabiei survive adverse environmental periods for several weeks $(21,28)$. Ascospores of D. rabiei also appear to be resistant to adverse environmental conditions (W. J. Kaiser and A. Trapero-Casas, unpublished data). When ascospores were discharged into sterile petri dishes and maintained at 20 to $23^{\circ} \mathrm{C}$ and 15 to $30 \% \mathrm{RH}$ for 1 month, about $15 \%$ of the ascospores germinated when cool WA was poured into the plates. Resistance of ascospores to desiccation and other environmental stresses may allow ungerminated spores to remain viable on the surface of chickpea leaves at low relative humidities and then to germinate and quickly infect the host during periods of high humidity. Resistance to adverse conditions also helps to explain why ascospores that are windborne for considerable distances are able to initiate widespread infections of large chickpea fields during cool, wet weather as has been observed in the Palouse region of eastern Washington and northern Idaho (12,25; W. J. Kaiser and A. Trapero-Casas, unpublished data).

Inoculum density of $A$. rabiei has been shown to be an important factor influencing disease severity (24). The relatively low 
disease severity ratings obtained in our inoculation experiments may be due to the low concentration of inoculum used $\left(2 \times 10^{4}\right)$. We were obliged to use this low level of inoculum because of the difficulties encountered in obtaining higher concentrations of ascospores from infested chickpea debris. Trapero-Casas and Kaiser (24) demonstrated that disease severity in chickpeas inoculated with conidia decreased with decreasing inoculum densities. At the lowest inoculum level tested $\left(4 \times 10^{4}\right.$ spores per $\left.\mathrm{ml}\right)$ in their study, disease severity in the same chickpea cultivar used in these studies was significantly lower than that obtained at higher inoculum densities. At this conidial concentration, disease severity after 14 days in the greenhouse at 18 to $26^{\circ} \mathrm{C}$ was about $56 \%$, whereas in the present study it was about $49 \%$.

Inoculation of different chickpea cultivars with ascospores of the pathogen showed that disease response of cultivars did not differ from those observed in inoculations with conidia or under field conditions (24).

In an earlier study, Trapero-Casas and Kaiser (24) demonstrated that interrupted wetness periods after inoculation with conidia of A. rabiei greatly affected disease severity. When dry periods began immediately after inoculation, there was a significant increase in disease severity compared with plants receiving the same wet period without drying. In the present study, we observed a similar effect on disease severity when variable dry periods began immediately after inoculation with ascospores and conidia of the pathogen. Differences between ascospores and conidia were scarce in this experiment, although ascospores caused higher disease severity in the continuous wetness treatment and lower disease severity when variable dry periods began immediately after inoculation. Ascochyta blight epidemics often occur in countries with temperate or semiarid climates where extended periods of wet weather occur infrequently during the spring when the crop is usually planted. The ability of the ascospores (and conidia) to tolerate intermittent dry periods during the germination and infection process, as we observed in this study, may explain why the disease can be so devastating to the chickpea crop in these countries.

Precise data on the effects of various environmental factors on the epidemiology of Ascochyta blight is essential in predicting the risk of the disease in different regions with different crop management practices, and in developing a reliable disease forecasting program to assist growers in applying foliar fungicides for disease control. Trapero-Casas and Kaiser (24) made a detailed study of the effects of temperature and leaf wetness on disease development under controlled conditions using conidial inoculum. The results of the present study on the effects of temperature and relative humidity on germination and germ tube growth of ascospores and conidia needs to be taken into consideration in the development of a disease forecasting system for Ascochyta blight. The teleomorph of $A$. rabiei has been found in several countries $(12,25)$. Ascospores are an important primary inoculum for Ascochyta blight epidemics in Spain (26) and the United States (25), and their importance in disease development may be demonstrated in other countries where the teleomorph occurs $(4,6,7,9,12-14)$.

\section{ACKNOWLEDGMENTS}

This research was supported in part by grants IPA-8510/017 and CCA$8510 / 30$ from the U.S.-Spain Joint Committee for Scientific and Technological Cooperation, and AGR 89-0260 from the CICYT, Spanish Ministry of Education and Science. We thank B. C. Hellier and F. LuqueMárquez for valuable technical assistance.

\section{LITERATURE CITED}

1. Alderman, S. C., and Beute, M. K. 1986. Influence of temperature and moisture on germination and germ tube elongation of Cercospora arachidicola. Phytopathology 76:715-719.
2. Arauz, L. F., and Sutton, T. B. 1989. Temperature and wetness duration requirements for apple infection by Botryosphaeria obtusa. Phytopathology 79:440-444.

3. Arauz, L. F., and Sutton, T. B. 1989. Influence of temperature and moisture on germination of ascospores and conidia of Botryosphaeria obtusa. Phytopathology 79:667-674.

4. Armstrong, C. L., Chongo, G., Gossen, B. D., and Duczek, L. J. 2001. Mating type distribution and incidence of the teleomorph of Ascochyta rabiei (Didymella rabiei) in Canada. Can. J. Plant Pathol. 23:110-113.

5. Dean, R. A. 1997. Signal pathways and appressorium morphogenesis. Annu. Rev. Phytopathol. 35:211-234.

6. Galloway, J., and MacLeod, W. J. 2003. Didymella rabiei, the teleomorph of Ascochyta rabiei, found on chickpea stubble in Western Australia. Aust. Plant Pathol. 32:127-128.

7. Gamliel-Atinsky, E., Shtienberg, D., Vintal, H., Nitzni, Y., and Dinoor, A. 2005. Production of Didymella rabiei pseudothecia and dispersal of ascospores in a Mediterranean climate. Phytopathology 95:1279-1286.

8. Harris, R. F., Gardner, W. R., Adebayo, A. A., and Sommers, L. E. 1970. Agar dish isopiestic equilibration method for controlling the water potential of solid substrates. Appl. Microbiol. 19:536-537.

9. Haware, M. P. 1987. Occurrence of perfect stage of Ascochyta rabiei in Syria. Int. Chickpea Newsl. 17:29-30.

10. Jones, E. B. G. 1994. Fungal adhesion. Mycol. Res. 98:961-981.

11. Kaiser, W. J. 1973. Factors affecting growth, sporulation, pathogenicity, and survival of Ascochyta rabiei. Mycologia 65:444-457.

12. Kaiser, W. J. 1997. Inter- and intranational spread of ascochyta pathogens of chickpea, faba bean, and lentil. Can. J. Plant Pathol. 19:215-224.

13. Kaiser, W. J., and Küsmenoglu, I. 1997. Distribution of mating types and the teleomorph of Ascochyta rabiei on chickpea in Turkey. Plant Dis. 81:1284-1287.

14. Kaiser, W. J., and Okhovat, M. 1996. Distribution of Didymella rabiei, the teleomorph of Ascochyta rabiei in Iran. Iran. J. Plant Pathol. 32: 158-162.

15. Kovachevski, I. C. 1936. The blight of chickpea (Cicer arietinum), Mycosphaerella rabiei n. sp. (In Bulgarian with an English summary). Ministry of Agriculture and Natural Domains, Plant Protection Institute, Sofia, Bulgaria.

16. Louis, E., and Cooke, R. C. 1985. Conidial matrix and spore germination in some plant pathogens. Trans. Br. Mycol. Soc. 84:661-667.

17. Morgan, W. C., and Parbery, D. C. 1977. Ascospore liberation, germination, and attachment to host surface by Pseudopeziza medicaginis. Aust. J. Agric. Res. 28:777-784.

18. Navas-Cortés, J. A., Trapero-Casas, A., and Jiménez-Díaz, R. M. 1998. Phenology of Didymella rabiei development on chickpea debris under field conditions in Spain. Phytopathology 88:983-991.

19. Nene, Y. L., and Reddy, M. V. 1987. Chickpea diseases and their control. Pages 233-270 in: The Chickpea. M. C. Saxena and K. B. Singh, eds. CAB International, Oxon, UK.

20. Robinson, R. A., and Stokes, R. H. 1955. Electrolyte Solutions. Academic Press, New York.

21. Sattar, A. 1933. On the occurrence, perpetuation, and control of gram (Cicer arietinum L.) blight caused by Ascochyta rabiei (Pass.) Labrousse, with special reference to Indian conditions. Ann. Appl. Biol. 20:612632 .

22. Saxena, M. C., and Singh, K. B. (eds.) 1984. Ascochyta blight and winter sowing of chickpeas. Martinus Nijoff/Dr. W. Junk Publishers, Hague, the Netherlands.

23. Sutton, T. B., and Arauz, L. F. 1991. Influence of temperature and moisture on germination of ascospores and conidia of Botryosphaeria dothidea. Plant Dis. 75:1146-1149.

24. Trapero-Casas, A., and Kaiser, W. J. 1992. Influence of temperature, wetness period, plant age, and inoculum concentration on infection and development of Ascochyta blight of chickpea. Phytopathology 82:589596.

25. Trapero-Casas, A., and Kaiser, W. J. 1992. Development of Didymella rabiei, the teleomorph of Ascochyta rabiei, on chickpea straw. Phytopathology 82:1261-1266.

26. Trapero-Casas, A., Navas-Cortés, J. A., and Jiménez-Díaz, R. M. 1996. Airborne ascospores of Didymella rabiei as a major primary inoculum for ascochyta blight epidemics in chickpea crops in southern Spain. Eur. J. Plant Pathol. 102:237-245.

27. Weltzien, H. C., and Kaack, H. J. 1984. Epidemiological aspects of chickpea Ascochyta blight. Pages 35-44 in: Ascochyta Blight and Winter Sowing of Chickpeas. M. C. Saxena and K. B. Singh, eds. Martinus Nijhoff/Dr. W. Junk Publishers, Hague, the Netherlands.

28. Zachos, D. G., Panagopoulos, C. G., and Makris, S. A. 1963. Recherches sur la biologie, l'épidémiologie et la lutte contre l'anthracnose du poischiche. Ann. Inst. Phytopathol. Benaki N.S. 5:167-192. 